\title{
Subject Characteristics Subcategory
}

National Cancer Institute

\section{Source}

National Cancer Institute. Subject Characteristics Subcategory. NCI Thesaurus. Code C83402.

A subdivision of subject characteristics data. 